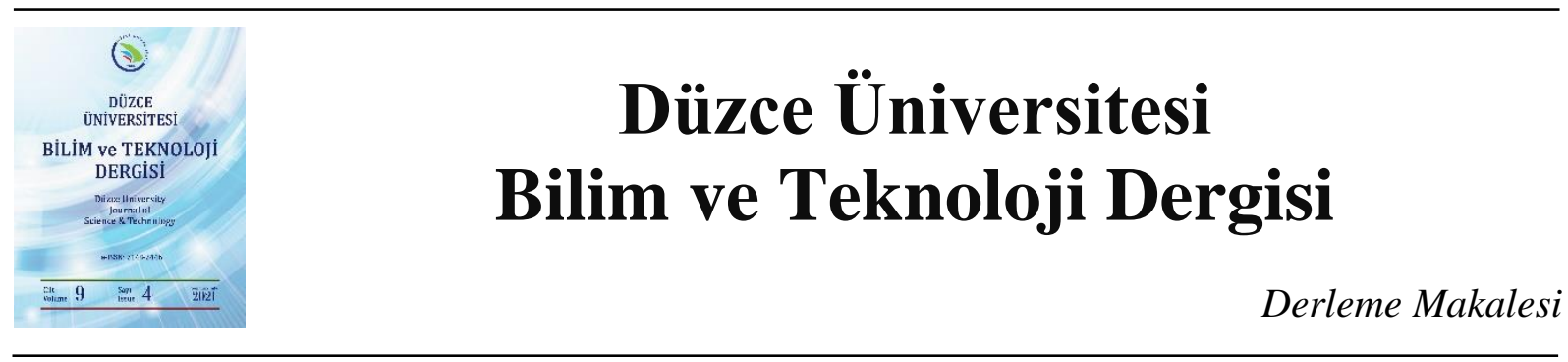

\section{Nanosentezde Yeşil Mühendislik Kavramı ve Çevre Mühendisliğindeki Yeri}

\author{
Şennur Merve YAKUT ${ }^{\mathrm{a}, \mathrm{b}^{*}}$, (D) Mustafa KARATAŞ ${ }^{\mathrm{b}}$ \\ ${ }^{a}$ Çevre Mühendisliği Bölümü, Mühendislik Mimarlık Fakültesi, Nevşehir Hacı Bektaş Veli Üniversitesi, \\ Nevşehir, TÜRKIYYE \\ ${ }^{b}$ Çevre Mühendisliği Bölümü, Mühendislik Fakültesi,, Aksaray Üniversitesi, \\ Aksaray, TÜRKIYE \\ * Sorumlu yazarın e-posta adresi:sennurmerve@nevsehir.edu.tr
}

DOI: 10.29130/dubited.799609

\begin{abstract}
$\underline{\mathrm{O} Z}$
Bu çalışmada ağırlıklı olarak, son yıllarda artan çevreci yaklaşıma uygun yeşil nanomalzemelerin üretimi ve çevre mühendisliğindeki kullanım alanlarına değinilmektedir. Bilim insanları, özellikle nüfus artışı ve endüstrileşme sonucunda ortaya çıkan çevre kirliliği sonucunda, bu kirliliği durdurmak ya da en aza indirgemek için çalışmalar gerçekleştirmektedir. Bu çalışmaların büyük bir kısmı geleneksel kimyasal içerikli yöntemlere dayanmaktadır. Ancak, bu durumda bir taraftan kirleticiler etkin bir şekilde giderilirken bir taraftan da ikincil bir kirlenme ortaya çıkmaktadır. Bu yüzden doğal yollarla üretilmiş nanopartiküller önem kazanmıştır. Çevreci yaklaşımla sentezlenen nanopartiküler, tamamen biyolojik kökenli materyaller kullanılarak oluşturulmaktadır. Böylece çevre için zararlı çözücü maddeler yerine tamamen doğal bileşenler kullanılmakta ve arıtım verimi yüksek nanomalzemeler üretilmektedir. Sonuç olarak, yeşil kimya ve nanoteknoloji kavramları birleştirilerek gerçekleştirilen bu nanomalzemelerin gelecekte daha çok kullanılacağı düşünülmektedir.
\end{abstract}

Anahtar Kelimeler: Arıtım, Nanoteknoloji, Yeşil sentez

\section{Green Engineering in Nanosynthesis and Its Place in Environmental Engineering}

\begin{abstract}
This study mainly focuses on the production of green nanomaterials suitable for the environmentalist approach that has increased in recent years and their use in environmental engineering. Scientists carry out studies to stop or minimize this pollution, especially as a result of population growth and industrialization. Most of these studies are based on traditional chemical methods. However, in this case, while pollutants are effectively removed, a secondary pollution arises. Therefore, naturally produced nanoparticles have gained importance. The nanoparticles which synthesized with an environmental approach are create using completely biological materials. Thus, completely natural components are used instead of solvents harmful to the environment and nanomaterials with high treatment efficiency are produced. As a result, it is thought that these nanomaterials, which are realized by combining the concepts of green chemistry and nanotechnology, will be used more in the future.
\end{abstract}

Keywords: Treatment, Nanotechnology, Green synthesis

Geliş: 06/10/2020, Düzeltme: 27/04/2021, Kabul: 03/05/2021 


\section{GIRIS}

Endüstrileşme ve nüfus sayısının hızla arttı̆̆ 1 son yüzyılda, çevre kirliliği konusu büyük önem teşkil etmektedir. Çevre kirliliği denilince özellikle su kirliliği, hava kirliliği, toprak kirliliği konularında yoğunlaşılmaktadır. Doğanın dengesinin bilinçsiz insan faaliyetleri ile bozulmasıyla gerçekleşen bu etkenler sonucu çevresel konularda endişeler gün geçtikçe artmaktadır. Alınan bazı önlemler ile bu kirliliklerin önüne geçilmesi hedeflense de çevre kirliliği tam anlamıyla yok edilememektedir. Dolayısıyla günümüzde çevre kirliliğini önlemek ya da azaltmak için fazlaca çalışma yapılmaktadır. Ancak, bu çalışmaların bir kısmı ilgili ortamdaki kirleticiyi giderirken başka ortamlardaki habitat için olumsuz etkiler oluş̧urabilmektedir. Örneğin su arıtımında kullanılan bir takım kimyasal maddeler suyu arıtmakta fakat kullanılan kimyasalların alıcı ortama karışmasıyla o ortamda bulunan canlılar negatif olarak etkilenebilmektedir. Bu sorunların ortaya çıkması, çevreye daha az ya da hiç zarar vermeyecek teknolojilerin geliştirilmesini sağlamıştır.

Günümüzde, çevre dostu yaklaşımların bir dalı olarak "yeşil kimya" kavramı önümüze çıkmaktadır. Özellikle 2000 yılından sonra bu kavram eğitim alanında da öğrencilere anlatılmaya başlanmıştır. Yeşil kimyanın başlıca özellikleri; ekonomik olması, çevre dostu olması ve diğer teknolojilere göre üzerinde çalışılmasının daha güvenilir olmasıdır [1]. Yeşil kimyanın asıl amacı, atıkları ortaya çıktıktan sonra gidermektense atığın oluşumunu minimize etmek ya da atığın oluşumuna asla izin vermemektir [2]. Yeşil kimya kavramının yanında, yeşil mühendislik olgusu da meydana gelmektedir. Sürdürülebilirlik kavramı; çevresel, sosyal ve ekonomik kavramlarının birleşim kümesidir. Yeşil kimya ve yeşil mühendisliği sürdürülebilirlik kavramı ile bütünleştirmek gereklidir. Bu kapsamda, sürdürülebilir ve yeşil proseslerin dizayn edilmesinin sağlanması için hem kimyacılara hem de mühendislere görev düşmektedir. Geleneksel kimya ve mühendislik içerisine "yeşil" terimini eklemek başta zor bir kavram olarak görünse de sonuçları oldukça tatmin edici olacaktır. Bu kapsamdaki önemli bazı kavramlar şunlardır [3]:

1. Çevre sağlığı ve güvenliği açısından en uygun olan tepken seçilmelidir.

2. Araştırma ve geliştirme aşamasında oluşacak yan ürünler ve bunların oluşturacağı atıklar iyi bilinmelidir.

3. Seçilen malzemelerin, prosesin üretiminden başlayarak oluşan atıkların bertarafına kadar geçen tüm süreçleri planlanmalıdır.

4. Proses dizayn edilip geliştirilirken ham madde ve enerji ihtiyaçları mümkün olduğunca minimize edilmelidir.

5. Kullanılacak ham malzemelerin yenilenebilir kaynaklardan olması sağlanmalıdır.

Nanopartikül sentezi günümüz mühendislik koşullarında oldukça gelişmiştir. Bu nanoparçacıklar çevre mühendisliğinde özellikle su arıtımında adsorban ve katalizör olarak kullanılmakta ve başarılı sonuçlar göstermektedir. Ancak bir dizi kimyasal üretim aşamalarında kullanılan çözücü, indirgeyici maddeler çevresel açıdan endişeleri arttırmaktadır. Çünkü bu maddeler insan ve çevre için ekstra bir kirlilik yükü oluşturmakta ve aynı zamanda sağlık açısından da risk oluşturmaktadır. İşte bu nedenlerden dolayı nanopartikül üretiminde, yeşil mühendislik prensibinin benimsendiği bir yol izlemek çok önemlidir [4]. Çevre dostu ve biyouyumlu malzemelerin kullanımıyla oluşan nanopartiküllerin sentezinde, çözücü olarak tercihen suyun kullanımı, ultrases, mikrodalga, biyolojik yöntemler, reaksiyonların oda sıcaklığında gerçekleşmesi gibi teknikler kullanılmaktadır. Bu tekniğe de "yeşil sentez" adı verilmektedir. Son yıllarda özellikle bitki ekstraktı gibi doğal ürünler kullanılarak gerçekleşen nanopartikül üretimi çalışmaları çoğalmaktadır [5-7]. Bitki ekstaktından başka, bakteri, maya, alg gibi mikroorganizmalar da kullanılabilmektedir. Yapılan çalışmalar, bitkisel kaynaklı nanopartiküllerin daha stabil ve hızlı olduğunu göstermektedir [8]. Bitki ekstraktı ile gerçekleştirilen yeşil sentezde, metal tuzları kullanımı oldukça yaygındır. Böylece metal tuzları indirgenerek bitki bazlı nanopartiküllerin üretimi gerçekleşmiş olmaktadır [9]. 


\section{NANOMALZEMELER VE MÜHENDİSLİK ALANINDAKİ UYGULAMALARI}

\section{A. NANOMALZEMELER VE ÇEVRE MÜHENDISLIĞĞINDE KULLANIMI}

Nanoteknoloji kavramı 1960'lı yılların sonlarından beri geliştirilmektedir [10]. Nanoteknoloji terimi ilk kez Norio Taniguchi isimli bir bilim insanı tarafından, "Atom-atom ya da molekül-molekül bozma, ayırma ve birleştirme işlemlerine nanoteknoloji denir" şeklinde ifade edilmiştir. Nanoteknoloji; çevre, malzeme, sağlık, ziraat, uzay gibi birçok alanda kullanılmakta ve üzerinde gerçekleştirilen çalışmalar da her geçen gün artmaktadır [11]. Tanım olarak, 100 nanometreden küçük, geniş yüzey alanına sahip, fiziksel ve kimyasal olarak çeşitli özellikler gösteren yapılar nanomalzeme olarak anılmaktadır. Nanomalzemeler, Amerika Birleşik Devletleri Çevre Koruma Ajansı tarafından 4 kategoriye ayrılmıştır. Bunlar; karbon bazlı, metal oksit bazlı, metal bazlı, polimerik yapıda ve yığın form içerisinde kompozitlerdir [12].

Çevre Mühendisliği alanında özellikle son birkaç yıldan beri, nanoteknoloji alanında çalışmalar artış göstermektedir. Geleneksel metotların kullanımına alternatif olarak nanomalzemelerin kullanımıyla hem daha çevre dostu hem de daha ekonomik malzemeler elde edilmeye başlanılmıştır. Nanomalzeme ya da mühendislikte kullanılan şekliyle nanopartiküller, çevre mühendisliğinde hava kirliliği, su arıtımı, toprak iyileştirme gibi çeşitli alanlarda kendine yer bulmuştur. Örneğin; demir, titanyum, çinko gibi metaller hem içme suyu arıtımında hem de atıksuların arıtımında kullanılmaktadır [13].

\section{A. 1. Nanopartikül Sentez Yöntemleri}

Nanopartikül sentezi temel olarak iki başlık altında incelenmektedir. Bunlar; "yukarıdan aşağıya" ve "aşağıdan yukarıya" adı verilen yöntemlerdir. Yukarından aşağıya yöntemi, kimyasal ya da mekanik müdahaleler ile büyük boyuttaki maddelerin nano boyuta indirgenmesi prensibine dayanmaktadır. Bilyeli ögütücüler ile yapılan işlem buna bir örnektir. Ayrıca bu işlemde yüksek enerji tüketimi gerçekleşmektedir. Aşağıdan yukarıya metodunda ise atom ya da moleküllerin bir takım kimyasal tepkimelerle büyütülmesi işlemi gerçekleşir. Bu metot, fiziksel olan yukarıdan aşağıya metodunun aksine kimyasal reaksiyonlara dayanmaktadır. Örneğin; buhar birikimi, sol- jel prosesi, sprey ve lazer piroliz, yoğunlaştırma, aerosol prosesler ve biyoredüksiyon buna örnektir [14]. İki başlıkta toplanacak olursa, fiziksel ve kimyasal yöntemlerden bazıları özet olarak Tablo 1'de gösterilmektedir [15].

Tablo 1. Nanopartikül sentezinde kullanılan bazı metotlar

\begin{tabular}{cc}
\hline Fiziksel Metotlar & Kimyasal Metotlar \\
\hline Asal gaz yoğunlaşması & Ters misel \\
\hline Şiddetli plastik şekil değişimi & Kontrollü kimyasal çöktürme \\
\hline Yüksek enerjili bilyeli ögütme & Kimyasal buhar yoğunlaşması \\
\hline Ses ötesi atışla dövme & Sıvı alev püskürtme \\
\hline & Gaz fazda indirgeme \\
\hline & Sıvı fazda indirgeme \\
\hline
\end{tabular}

Doğada bulunan bazı malzemelerin içerisindeki moleküller, kimyasal ve elektriksel bağlarla bir arada bulunurlar. Laboratuvar şartlarında bu malzemeler birtakım işlemlerden geçirilerek nanomalzemeler elde edilir [16]. Fiziksel metotlarda genel olarak, enerji, basınç, mekanik yük gibi başlıklar etkiliyken, kimyasal metotlarda daha çok kimyasal bileşenler ya da gazların kullanımı sentez işlemlerini etkilemektedir.

\section{A. 2. Nanopartiküllerin Mühendislikteki Yeri}

Nanopartiküllerin üzerine yapılan araştırmaların çoğalması ve verimli sonuçlar elde edilmesiyle birçok alanda kullanımı artmıştır. Özellikle mühendislik alanında bu malzemelerin kullanılması sıklıkla 
karşımıza çıkmaktadır. Örneğin; pil yapımında, klasik lityum iyon pillerine alternatif olarak karbon nanotüplerin kullanımı üzerine araştırmalar yapılmaktadır. Çevre alanında, nanomalzemelerin geniş yüzey alanına sahip olmalarından yararlanılarak, arıtımda kullanım çalışmaları yapılmaktadır. Nanomalzemelerin değişken iletkenliklerinden yararlanılarak sensör olarak kullanımına ek olarak, yapı malzemesi olarak ve süper iletken madde olarak farklı mühendislik alanlarında da kullanımı mevcuttur. Biyomedikal alanında, nanomalzemelerden, nanobiyosensör olarak kullanılarak bazı hastalıkların tespitinde yararlanılmaktadır. Diğer bir mühendislik alanı olarak tekstil mühendisliğinde ise, kendi kendini temizleyen kumaşlar ve insanları dış hava şartlarından koruyan kumaşlar imal edilmektedir [17]. Tablo 2'de farklı mühendislik alanlarında kullanılan nanopartiküllere ait bazı örnekler verilmektedir.

Tablo 2. Farklı mühendislik dallarında nanopartikül kullanımına dair örnekler

\begin{tabular}{|c|c|c|c|}
\hline Uygulanan Yöntem & $\begin{array}{c}\text { Elde Edilen } \\
\text { Nanomalzemenin Cinsi }\end{array}$ & Kullanım Alanı & Kaynak \\
\hline Alginat ile Sentez & $\mathrm{Al}_{2} \mathrm{O}_{3}, \mathrm{ZnO}, \mathrm{ZrO}_{2}$ & Ağır Metal Giderimi & {$[18]$} \\
\hline Sol-Jel & $\mathrm{Cu}-\mathrm{TiO}_{2}$ & $\begin{array}{c}\text { Binalarda Enerji Verimliliğinin } \\
\text { Artırılmas1 }\end{array}$ & [19] \\
\hline Kaplama & $\begin{array}{l}\text { Zein (Misırda bulunan } \\
\text { bir protein) }\end{array}$ & $\begin{array}{c}\text { Tekstil Ürünlerine Hidrofobiklik } \\
\text { ve Antimikrobiyal Özellik } \\
\text { Kazandırımı }\end{array}$ & [20] \\
\hline Kimyasal Sentez & $\mathrm{MgO}$ & Atıksulardan Renk Giderimi & [21] \\
\hline $\begin{array}{c}\text { Kaplama, } \\
\text { Kendiliğinden } \\
\text { Yapılanma } \\
\end{array}$ & $\begin{array}{l}\text { Grafen/Gümüş Nanotel, } \\
\text { Gümüş Nanotel }\end{array}$ & Saydam İletken Elektrot Üretimi & [22] \\
\hline Kimyasal Sentez & $\begin{array}{l}\text { Nanokompozit Polietilen } \\
\text { Film }\end{array}$ & $\begin{array}{c}\text { G1da Ürünlerinin Raf Ömrünün } \\
\text { Uzatılmas1 }\end{array}$ & [23] \\
\hline $\begin{array}{c}\text { Kimyasal ve } \\
\text { Elektrokimyasal } \\
\text { Sentez }\end{array}$ & Polianilin Nanomateryal & $\begin{array}{c}\text { Yüksek Yüzey Alanı ve } \\
\text { İletkenliğe Sahip Malzeme } \\
\text { Üretimi }\end{array}$ & [24] \\
\hline Kimyasal Çöktüme & $\mathrm{ZnO}, \mathrm{NiO}$ & $\begin{array}{l}\text { LCD’ler için Yüksek Çözünürlük } \\
\text { Sağlayıı Malzeme Üretimi }\end{array}$ & [25] \\
\hline Elle Yatırma Yöntemi & $\begin{array}{c}\text { Poliakrilontiril, } \\
\text { Polivinilklorür ve } \\
\text { Termoplastik Poliüretan } \\
\text { Polimerlerinin } \\
\text { Nanofiberleri } \\
\end{array}$ & Nanokompozit Malzeme Üretimi & [26] \\
\hline Sol- Jel & $\mathrm{Ag}-\mathrm{ZnO}$ & Nanobiyosensör & [27] \\
\hline Kimyasal Sentez & Nişasta bazlı $\mathrm{SiO}_{2}$ & $\begin{array}{l}\text { Yüksek Performanslı Ahşap } \\
\text { Yapıştırıcısı }\end{array}$ & [28] \\
\hline
\end{tabular}

Teknolojik gelişmeler sonrasında nanopartiküllerin üretiminin her geçen gün artması, zamanla bu malzemelerin daha çevre dostu şekillerde üretimine yönelimi getirmiştir. Böylelikle bilimsel olarak hem gelişme sağlanacak hem de çevre için fazladan bir yük oluşturulmamış olacaktır. Yeşil sentez kavramının da yaygınlaşmasıyla, bilim insanlarının nanopartikül sentezlerini bu yaklaşım prensibini benimseyerek gerçekleştirmelerine olanak sağlanmıştır. Örneğin; Roy ve ark. [29], Klebsiella pneumoniae, Eschreichia coli ve Staphylococcus aureus bakterilerinin büyümesini önleyici, antibakteriyel bir gümüş nanopartikül sentezi gerçekleştirmişlerdir. Bunun için gümüş tuzları ve indirgeyici ajan olarak maydanoz yaprağ özütü kullanmışlardır. Elveren [30], siyanür tespiti için altın nanopartikül sentezi gerçekleştirmiştir. Altın nanopartikül sentezinde, melissa yaprağı, nar ve adaçayı kullanıp, adaçayı bazlı altın nanopartikül dışında diğer nanopartiküllerin plazmonik substrat olarak kullanımının uygun olduğunu tespit etmiştir. Sekmen [31], daha iyi iletkenliğe, elektrotransfer hızına ve elektrokatalitik aktiviteye sahip elektrot modifikasyonunda kullanılmak üzere, altın, gümüş, bakır, demir ve nikel nanopartikül sentezi gerçekleştirmiştir. Yeşil sentez metodunu kullanarak yaptığı 
çalışmada, bitki ekstraktı olarak; domates, salatalık, kabak, elma, erik, kereviz ve karnabahar özütleri kullanmış olup, elektrot modifiyesinde başarı sağlamıştır. Biyosensör olarak altın nanopartikülleri kullanan Kumar ve ark. [32], zencefil özütü kullanarak gerçekleştirdikleri çalışmalarında bu nanopartikülün, kanla doğrudan temasın olduğu durumlar için uygun olduğunu ifade etmişlerdir. Bahsedilen çalışmalarda genellikle bitkisel malzemeler kullanıldığı görülmektedir, ancak yeşil sentez sadece bitkisel kaynaklı yapılmamaktadır. Sebze ve meyvelere ek olarak alg, maya ve mantar kullanımına da rastlanılmaktadır [33- 35]. Vágó ve ark. [36], yaptıkları bir çalışmalarında indirgeyici ajan olarak Schizophyllum commune isimli bir mantar kullanmışlardır. Metal kaynağı olarak gümüş nitrat kullanarak elde ettikleri gümüş nanopartikülleri antibakteriyel bir madde olarak kullanarak başarı elde etmişlerdir.

\section{B. ÇEVRE MÜHENDİSLIĞİNDE NANOTEKNOLOJI}

Nanoteknolojinin günümüzün yükselen teknolojisi olması nedeniyle birçok alanda bu konuda yapılmış çalışmalar bu alanda da denenmeye başlanmıştır. Çevre mühendisliğinde bilhassa su arıtımı konusunda adsorban madde ya da katalizör olarak kullanımı oldukça göze çarpmaktadır. Sifır değerlikli demir nanopartiküller, toprak iyileştirmede ve radyoaktif atıklarda kullanımı göze çarpmaktadır. Hava kirliliği açısından ise, karbondioksit, azot bazlı gazlar, metan gazları, partikül maddeler gibi hava kirleticilerinin gideriminde geleneksel filtreler yerine, titanyum dioksit gibi nanomalzemeler kullanılmaktadır. Böylece kirleticilerin daha etkili filtrelenmesi elde edilmektedir [13]. Buna ek olarak çevre mühendisliğinde nanoteknolojinin kullanımının yanı sıra diğer mühendislik alanlarında da nanomalzeme üretilirken çevreye de zarar vermeme ilkesi benimsenmelidir. Çevresel alanlarda yapılan çalışmalarda elde edilen nanomalzemelerin arıtımda başarı sağladığı literatürdeki kaynaklarda açıkça görülmektedir.

Kale ve Kane [37], polivinilpirolidon polimeri ile stabilize edilmiş nikel nanopartiküller ile C. I. Reactive Blue 21 isimli boyarmadde gideriminde \% 98'lik verim ve ayrıca Kimyasal Oksijen İhtiyacı giderimini de sağlamışlardır. Ge ve ark. [38], kadmiyum, çinko, kurşun ve bakır ağır metallerinin gideriminde $\mathrm{Fe}_{3} \mathrm{O}_{4}$ nanopartikülleri kullanmışlardır. 3-aminopropiltrietoksisilon, akrilik asit ve krotonik asit kopolimerleri ile modifiye edilmiş demir nanopartikülleri ile $\mathrm{pH}, 5.5$ 'te yüksek oranda ağır metal giderimi gerçekleştirmişlerdir. İlaç kalıntısı giderimi üzerine yapılan bir çalışmada, Sarkar ve ark. [39], kalsiyum aljinat ile immobilize edilmiş $\mathrm{TiO}_{2}$ kullanmışlardır. Sonuç olarak, bir çeşit antibiyotik olan klorheksidin diglukonat, ibuprofen, atenolol ve karbamazepin etken maddeleri giderimi için kullanılan bu nanopartiküllerin ilaç kalıntısı gideriminde başarılı oldukları belirtilmiştir. Topuz ve Uyar [40], polisiklik aromatik hidrokarbon giderimi üzerine yaptıkları çalışmalarında silika nanopartikülleri kullanmışlardır. Çalışmalarında, modifiye ettikleri silika nanopartiküllerin, aktif karbon gibi sıklıkla kullanılan başarılı materyallere alternatif olarak kullanımının umut verici olduğunu belirtmişlerdir.

Birçok alanda artan teknolojik malzeme ihtiyaciyla, yeni, modifiye edilebilir malzeme üretimi göze çarpmaktadır. Bu nanoteknoloji kavramının tercih edilmesinin nedeni, daha küçük malzemenin verimi arttırması ve çoğunlukla bu malzemelerin hem ekonomik olması hem de performansının yüksek olmasıdır [41]. Buna ek olarak nanoteknolojinin ülkemizde son yıllarda tercih edilmeye başlaması bu alana olan ilgiyi arttırmakta ve çalı̧̧maların yaygınlaşmasıyla da nanomalzemeler ile ilgili yeni özellikler keşfedilmektedir. Özellikle çevre mühendisliği uygulamalarında, malzemenin yüzey alanının artmasıyla, o malzemenin kirletici giderme veriminin artması doğru orantılı olduğu düşünüldüğünden çoğunlukla küçük boyutlu malzemeler tercih edilmektedir. Ayrıca bu malzemelerin yeniden kullanım için olanak tanıması çevre mühendisliği açısından büyük önem arz etmektedir. Böylece hem kirletici maddelerin giderim verimi artacak hem de elde edilen malzeme tekrar tekrar kullanılacak ve çevre için fazladan bir kirlilik yükü oluşturulmayacaktır. Çevreye ekstradan kirlilik yükü oluşturmamak konusu üzerine gidildiğinde ise, nanomalzeme oluşturulurken (sentez aşamasında) daha doğa dostu malzemeler kullanımı ya da tamamen biyolojik kaynaklı ham maddelerin kullanımı göze çarpmaktadır. Bu sebeple diğer mühendislik alanlarında olduğu gibi çevre mühendisliği çalışmalarında da nanoteknolojik ürünler kullanılırken ürünlerin daha önceden bahsedilen "yeşil sentez" metoduna göre elde edilmesi, üzerinde ayrıca durulması gereken önemli bir konudur. 


\section{YEȘIL SENTEZIN CEVRE MÜHENDISLIĞİiNDE UYGULANMASI}

Çevre mühendisliği diğer mühendislik dallarından farklı olarak doğal kaynakları tüketmek yerine, bu kaynakları korumaya ya da bozulan ortamı eski haline getirme prensibine dayalı bir mühendislik dalıdır. Dolayısıyla ekosistem için en uygun şartlar oluşturulmalıdır. Yeşil kimya gibi yaklaşımlarla bu şartların elde edilmesi sağlanmaktadır. Böylece hem kirlilik azaltılmış veya giderilmiş olacak hem de çevre kirletilmemiş olacaktır.

Bunun yanında, kullanılan nanomalzemelerin kullanılmaya başlandığı aşamadan itibaren davranışları da bir diğer önemli konudur. Bu malzemelerin, nüfuz ettikten sonra form değişikliğine uğrayıp uğramadığı, atık kalıntı olarak kalıp kalmadığı gibi konular da ekstra bir inceleme konusudur [42]. Genel olarak nanopartikül/nanomalzeme sentezi; metal bazl, karbon bazlı, polimer bazlı ve seramik bazlı gerçekleşmekte olduğu daha önceden belirtilmişti. Yeşil sentezde ise; en sık kullanılan metal bazlı nanopartikül sentezidir [8]. Metal bazlı nanopartikül sentezinin daha çok tercih edilmesinin sebebi; metallerin üstün kimyasal, mekanik, manyetik ve optik özellikleri göstermesinden dolayıdır [43]. Önceki bölümlerde de bahsedildiği gibi metal nanopartiküller farklı bilim alanlarında kullanılmakta olup, bu bölümde ise çevre mühendisliği alanında yapılan çalışmalara değinilecektir.

\section{A. TOPRAK KİRLİLIĞİ GIDERIMINDE YEŞİL SENTEZ}

Toprak, canlılar için önemli olan temel yaşam kaynaklarından biridir. İçerisinde barınan canlılar doğal ekosistemin birer parçaları olduklarından bu ortamın kirlenmemiş olması çok önemlidir. İşte bu yüzden toprak kirliliği kavramı birçok alanı olumsuz etkileyen bir kavramdır. Çevre mühendisliğinde kirlenmiş toprakların ıslahı üzerine çalışmalar yoğunlaşmaktadır. Toprak kirliliğinin giderimi için pahalı yöntemlere (bölgenin kazılarak kirliliğin bertarafı, toprak yıkama, termal desorpsiyon gibi) alternatif olarak nanopartiküllerin kullanımı dikkat çekmektedir [44]. Tablo 3'de toprak kirliliğinin giderimi için kullanılan nanopartiküllerle ilgili literatürde bulunan bazı kaynaklar derlenmiştir.

Tablo 3. Toprak kirliliğinin gideriminde kullanılan nanopartiküller

\begin{tabular}{cccc}
\hline Yeşil Sentez Kaynağı & Kirlilik Kaynağı & $\begin{array}{c}\text { Kullanılan Nano Metal } \\
\text { Kaynağı }\end{array}$ & Kaynak \\
\hline Yeşil Çay & Ağır Metal, Cr (VI) & $\begin{array}{c}\text { Kil destekli, sıfir değerlikli } \\
\text { demir (nZVI) }\end{array}$ & {$[45]$} \\
\hline $\begin{array}{c}\text { Euphorbia cochinchinensis } \\
\text { Yaprağ } 1\end{array}$ & Ağır Metal, As & Demir (Fe) & {$[46]$} \\
\hline $\begin{array}{c}\text { Br assica alba, Ficus } \\
\text { sycomorus, Ipomoea } \\
\text { carnea }\end{array}$ & İnsektisit (Klorfenapir) & Demir ve Gümüş & {$[47]$} \\
\hline $\begin{array}{c}\text { Sapindus mukorossi } \\
\text { Yeşil Mango Kabuğu }\end{array}$ & $\begin{array}{c}\text { Bazı PAHlar (polisiklik } \\
\text { aromatik hidrokarbonlar) }\end{array}$ & Demir hekzasiyanoferrat & {$[48]$} \\
\hline A. indica & Petrol Hidrokarbonları & Demir (nZVI) $^{\text {TiOO }}$ bazlı çinko & {$[49]$} \\
\hline hekzasiyanoferrat & {$[50]$} \\
\hline
\end{tabular}

Tablo 3'de verilen örnekler doğrultusunda yeşil sentez metodu ile elde edilen nanopartiküllerin, toprak kirliliği için özellikle önem teşkil eden, ağır metaller, polisiklik aromatik hidrokarbonlar ve zirai ilaçların gideriminde başarılı sonuçlar verdiği görülmektedir.

\section{B. SU ARITIMINDA YEŞIL SENTEZ}

Su, tüm canlılar için temel bir ihtiyaçtır. Dolayısıyla suyun korunması tüm insanlık için temel bir görev olmalıdır. Bu doğrultuda, su ile ilgili olarak özellikle çevre mühendisliği alanında oldukça fazla 
çalışma bulunmaktadır. Bu çalışmalar arttıkça, zamanla su arıtılırken başka kirliliklerin ortaya çıktığı tespit edilmiştir. Yani, suyun arıtımında kullanılan bazı malzemelerin ikincil bir kirlilik olarak atıksulara karışması bilim insanları tarafından endişe oluşturmaktadır. Dolayısıyla, bir kaynağı iyileştirirken, diğer kaynağa zarar vermemek için daha yeşil teknolojilerin kullanılması öncelikli hedefimiz olmalıdır. Çevreci bir prensip olan yeşil kimya, tam da bu noktada devreye girmektedir. Yeşil kimya yaklaşımıla yapılan çalışmaların amacı çevreye zarar vermemek ya da en az zararla atlatmaya, kısacası su kalitesini iyileştirmeye yöneliktir. Su arıtımında temel olarak iki başlık vardır: Atıksu arıtımı ve içme suyu arıtımı. Hem atıksuların hem de içme sularının belirli bir kalite standartında olması için iyileştirme çalışmaları diğer bir deyişle arıtım çalışmalarında kullanılan yeşil nanopartiküler ile ilgili literatürde bulunan bazı çalışmalar Tablo 4'te verilmektedir.

Tablo 4. Su arttımında kullanilan nanopartiküller

\begin{tabular}{|c|c|c|c|}
\hline Yeşil Sentez Kaynağı & Kirlilik Kaynağı & $\begin{array}{c}\text { Kullanılan Nano } \\
\text { Metal Kaynağı }\end{array}$ & Kaynak \\
\hline Punica granatum yaprağ & Metilen Mavisi & $\mathrm{CuO}$ & [51] \\
\hline Çay yaprakları & Monoklorobenzen & FeNP & [52] \\
\hline D. vulgaris & $\begin{array}{c}\text { Bazı ilaç kalıntıları } \\
\text { (17ß-estradiol, sülfametoksazol } \\
\text { ve siprofloksasin) }\end{array}$ & PtNP & [53] \\
\hline $\begin{array}{l}\text { Rosa damascene, Thymus } \\
\text { vulgaris ve Urtica dioica }\end{array}$ & $\mathrm{Cr}(\mathrm{VI})$ & nZVI & [54] \\
\hline $\begin{array}{c}\text { Mangifera indica, Murraya } \\
\text { Koenigii, Azadiracta indica, } \\
\text { Magnolia champaca, }\end{array}$ & $\begin{array}{l}\text { Evsel Atıksu (KOİ, Amonyum } \\
\text { nitrojen, fosfor) }\end{array}$ & FeNP & [55] \\
\hline Murt yaprağ1 & Telon Blue AGLF & $\mathrm{CuO}$ & [56] \\
\hline Ceratonia siliqua (keçi boynuzu) & Amoksisilin & $\mathrm{FeONP}$ & [57] \\
\hline $\operatorname{Alg}($ Anabaena cylindrica $)$ & İçme Suyu Dezenfeksiyonu & $\mathrm{CuO}$ & [58] \\
\hline Spirulina sp. & Tetrasiklin & $\mathrm{TiO}_{2}$ & [59] \\
\hline Silika & İçme Suyu Dezenfeksiyonu & $\mathrm{Cu}(\mathrm{CAS})$ & [60] \\
\hline Senegal akasyası & Direct Blue 129 & $\mathrm{ZnO}$ & [61] \\
\hline Biophytum sensitivum & $\begin{array}{c}\text { Metilen mavisi ve Metilen } \\
\text { turuncusu }\end{array}$ & AgNP & [62] \\
\hline
\end{tabular}

Tablo 4'te verilen bilgiler doğrultusunda, çevre mühendisliğinde bu nanopartikülerin özellikle atıksu arıtımında kullanıldığ 1 görülmektedir. Endüstri kaynaklı atıksulardan boyar madde giderimi ve ağır metal giderimi sıklıkla karşımıza çıkmakta olduğundan yapılan çalışmalar genellikle bu alanlarda gerçekleşmiştir. Deneysel sonuçlara baktığımızda oldukça verimli sonuçlara rastlanılmakta ve bu malzemelerin daha büyük alanlarda kullanımı beklenilmektedir. İçme sularında ise çalışmalar genellikle dezenfeksiyon üzerine gerçekleştirilmektedir. Dezenfeksiyon işleminde özellikle ortaya çıkan toksik yan ürünler, bu dezenfektanların kullanımında şüphe oluşturmaktadır. Bu amaçla çevre dostu nanopartiküllerin kullanımı bu endişeleri azaltabilir ve maliyeti de düşürebilir. Bu konuda daha çok çalışmanın yapılmasıyla daha somut verilere ulaşılması çevrenin geleceği için büyük önem teşkil etmektedir.

\section{HAVA KİRLILIIĞİ VE KONTROLÜNDE YEŞILL SENTEZ}

Canlılar içinde bulundukları ortamda temiz havaya ihtiyaç duyarlar. Hava kalitesinin düşük olduğu ortamlarda kısa ve uzun vadede sağlık sorunları oluşmaktadır. Genel olarak hava kirleticiler doğal ve yapay sebeplerden ötürü ortaya çıkmaktadırlar. Doğal sebepler; yangınlar, tozlar, yanardağların püskürttüğ̈̈ küllerden kaynaklanan kirliliği ifade ederken, yapay sebepler; kentleşme ve endüstrileşme sonucu ortaya çıkan kirlilikleri ifade etmektedir [63]. Özellikle insan faaliyetleri sonucu açığa çıkan hava kirleticiler $\left(\mathrm{CO}, \mathrm{NOx}, \mathrm{SO}_{2}\right.$, uçucu organik bileşikler, polisiklik aromatik hidrokarbonlar (PAH) 
gibi) canlılar için ciddi tehlikeler oluşturmaktadır. Bu kirleticilerin hava yoluyla insanlara geçmesiyle insan vücudunda birikim yaparak özellikle kanser hastalıklarına sebep olduğu bilinmektedir.

Hava kirliliğinde nanoteknoloji membranlarla karbondioksit gideriminde, $\mathrm{TiO}_{2}$ kullanılarak da azot oksitlerin nitrik asite dönüşümünde kullanılabilmektedir [64].

Tablo 5'te hava kirliliği alanında yapılan yeşil çalışmalardan bazıları verilmektedir.

Tablo 5. Hava kirliliği gideriminde kullanılan yeşil nanopartiküller

\begin{tabular}{cccc}
\hline Yeşil Sentez Kaynağı & Kirlilik Kaynağı & $\begin{array}{c}\text { Kullanılan Nano } \\
\text { Metal Kaynağı }\end{array}$ & Kaynak \\
\hline Sarımsak (Allium sativum) & PAH'lar & $\mathrm{Ag}$ & {$[65]$} \\
\hline Kauçuk ağacı yaprağı (Ficus elastica $)$ & $\mathrm{SO}_{2}$ & $\mathrm{Ag}$ & {$[66]$} \\
\hline Yeşil Çay & Karbon monoksit $(\mathrm{CO})$ & $\mathrm{Pd}$ & {$[67]$} \\
\hline Jatropha curcas & Asetaldehit & $\mathrm{CeO}_{2}$ & {$[68]$} \\
\hline Ficus carica ve Euphorbia amygdaloides & Metan gazı tespiti & $\gamma-\mathrm{Fe}_{2} \mathrm{O}_{3}$ & {$[69]$} \\
\hline
\end{tabular}

Hava kirliliği, küresel olarak problem oluşturmakla birlikte, tüm dünya olarak ortak önlemlerin alınması gereken bir sorundur. Tablo 5 'te verilen bazı çalışmalarda da görüldüğü üzere hava kirleticilerden PAH'ların, karbon monoksit, kükürt dioksit gibi gazların gideriminde ve bazı gazların tespitinde yeşil nanopartiküllerin kullanımı son yıllarda artan bir durumdur. Küresel 1sınma, ozon tabakasının incelmesi gibi ciddi sorunlara yol açan hava kirleticilerin gideriminde yeşil teknolojilerin kullanılması umut vericidir.

\section{YERALTI SUYU ARITIMINDA YEŞIL SENTEZ}

Dünyamızda su kaynakları temel olarak iki bölümden oluşmaktadır: yüzeysel sular ve yeraltı suları. Yeraltı suları; yağmurlar, göl, nehir suları gibi kaynakların topraktan sızmasıyla oluşmaktadır. Sular topraktan sızarken birkaç katmandan geçtiği için bu aşamada kısmi bir filtreleme işleminden geçmektedir. Dolayısıyla, kalitesi yüksek bir su kaynă̆ı karşımıza çıkmaktadır. Bu sular genellikle, içme suyu olarak, tarımsal sulama suyu olarak ve endüstriyel amaçlarla kullanılabilmektedir. Ancak yeraltı sularının iyi korunmaması, bilinçsizce aşırı miktarda çekilmesi, foseptik sularının karışması, evsel ve endüstriyel atıksuların karışması bu sular için tehlike oluşturmaktadır [70].

Aşağıda verilen Tablo 6'da yeraltı sularının çevreci yaklaşımla üretilmiş nanopartiküllerle arıtımı üzerine yapılan bazı çalışmalar gösterilmektedir.

Tablo 6. Yeraltı ve sızıntı suyu arıtımında kullanılan yeşil nanopartiküller

\begin{tabular}{cccc}
\hline Yeşil Sentez Kaynağı & Kirlilik Kaynağı & $\begin{array}{c}\text { Kullanılan Nano } \\
\text { Metal Kaynağı }\end{array}$ & Kaynak \\
\hline Yeşil Çay & Yeraltı suyunda Cr(VI) & nZVI & {$[71]$} \\
\hline Citrus paradisi & Yeraltı suyunda patojen ve florür & $\mathrm{Ag} / \mathrm{MgO}$ & {$[72]$} \\
\hline Yeşil Çay & Yeraltı suyunda $\mathrm{Cr}(\mathrm{VI})$ & $\mathrm{nZVI} / \mathrm{Ni}$ & {$[73]$} \\
\hline Yeşil Çay & Yeraltı suyunda Cr(VI) & Demir/Cu & {$[74]$} \\
\hline Biyokömür & Yeraltı suyunda Cr(VI) & nZVI & {$[75]$} \\
\hline Moringa oleifera & Yeraltı suyunda nitrat & $\mathrm{Fe}$ & {$[76]$} \\
\hline
\end{tabular}

Tablo 6' da görüldüğü üzere yeraltı suları için çoğunlukla krom iyonu giderimi üzerine çalışmalar bulunmaktadır. Kromun +6 değerlikli yapısına çoğunlukla evsel ve endüstriyel atıksuların yeraltına sızması sonucunda rastlanılmaktadır [77]. Dolayısıyla dış kaynaklı bu metalin giderimi önem kazanmaktadır. Bunun dışında; nitrat, florür, bazı mikroorganizmaların da yeraltı sularından giderimi üzerine yapılmış çalışmalara da rastlanılmaktadır. Nanomalzemelerin boyutları gereği geniş yüzey alanına sahip olmalarından dolayı kirletici maddeleri daha iyi adsorbe edeceği düşünülmektedir. 
Yeraltı sularının kalitesine bakıldığında içme suyu olarak iyi bir kaynak olmasından dolayı bu suların arıtımında yeşil yaklaşımlı nanomalzemelerin kullanımının artmasının ve üzerine yapılan araştırmaların çoğalması umut vericidir.

\section{IV.SONUC}

Çevre dostu, eko-sürdürülebilir teknolojiler her zaman dikkat çekmektedir. Bu kapsamda karşımıza "yeşil kimya", "çevre dostu" gibi kavramlar çıkmaktadır. Bu kavramların günümüz teknolojisine uyarlanmasıyla "yeşil sentez" adı verilen hem teknolojik hem de çevre dostu olan bir sentez metodu ortaya çıkmıştır. Yeşil sentezde esas olan geleneksel kimyasal çözücülere alternatif olarak doğada kolayca bulunan tamamen organik yapıların kullanılmasıdır. Farklı birçok mühendislik alanında nanomalzemeler kullanılmakta ancak bu malzemeler gerçekleştirilirken çevreye zarar verilmemesi gerektiği unutulmamalıdır. Çevre mühendisliğinde ise su arıtımı başta olmak üzere, toprak kirliliğinde, hava kalitesi iyileştirmede, yeraltı sularının arıtılması gibi konularda yeşil nanomalzemelerin kullanımına rastlanılmaktadır. $\mathrm{Bu}$ malzemelerin kullanımıyla yüksek verimlerin elde edilmesi, geleneksel nanomalzemelerin kullanımına bir alternatif olacağını düşündürmektedir. Böylece hem arıtım gerçekleşecek hem de çevre için bir yük oluşturulmamış olacaktır. Ayrıca ekonomik ve kolayca uygulanabilir olması en büyük avantajlarındandır. Zararlı çözücüler yerine organik maddelerin kullanılmasıyla, sentez aşamasında çalışan kişilerin sağlığı da olumsuz olarak etkilenmemiş olacaktır.

TEŞEKKÜR: Bu derleme çalışması 2020-039 No'lu Aksaray Üniversitesi BAP Birimi tarafından desteklenen doktora tez projesinin bir bölümüdür.

\section{KAYNAKLAR}

[1] Z. Gerçek, "Kimya'nın yeni rengi: yeşil kimya," Yükseköğretim ve Bilim Dergisi/Journal of Higher Education and Science, c. 2, s. 1, ss. 50-53, 2012.

[2] O. Sogut ve B. Çelebi, "Daha temiz analizler: yeşil kimya," Düzce Üniversitesi Bilim ve Teknoloji Dergisi, c. 8, s. 1, ss. 160-175, 2020.

[3] C. Jiménez-González, D. J. C. Constable, Yeşil Kimya ve Mühendislik Pratik Bir Tasarım Yaklaşımı,1. Baskıdan çeviri, Ankara, Türkiye: Nobel Yayıncılık, 2016, T. K. Aşkar, Çev., ss. 670673.

[4] Y. Wang, D. O'Connor, Z. Shen, I. M. Lo, D. C. Tsang, S. Pehkonen, S. Pu and D. Hou, "Green synthesis of nanoparticles for the remediation of contaminated waters and soils: Constituents, synthesizing methods, and influencing factors," Journal of Cleaner Production, vol. 226, pp. 540-549, 2019.

[5] O. V. Kharissova, H. R. Dias, B. I. Kharisov, B. O. Pérez and V. M. J. Pérez, "The greener synthesis of nanoparticles," Trends in biotechnology, vol. 31, no. 4, pp. 240-248, 2013.

[6] B. Kumar, K. Smita, L. Cumbal, A. Debut and Y. Angulo, "Biofabrication of copper oxide nanoparticles using Andean blackberry (Rubus glaucus Benth.) fruit and leaf," Journal of Saudi Chemical Society, vol. 21, pp. S475-S480, 2017.

[7] R. Yuvakkumar, J. Suresh, A. J. Nathanael, M. Sundrarajan and S. I. Hong, "Novel green synthetic strategy to prepare $\mathrm{ZnO}$ nanocrystals using rambutan (Nephelium lappaceum L.) peel extract and its antibacterial applications," Materials Science and Engineering: C, vol. 41, pp. 17-27, 2014. 
[8] S. Gündüz, "Manyetik demir nanopartiküllerin yeşil sentez metodu ile üretilmesi ve nanobiyosensör olarak kullanımının incelenmesi," Yüksek Lisans tezi, Nano Bilim ve Nano Mühendislik Anabilim Dalı, Atatürk Üniversitesi, Erzurum, Türkiye, 2018.

[9] S. Saranya, A. Eswari, E. Gayathri, S. Eswari and K. Vijayarani, "Green synthesis of metallic nanoparticles using aqueous plant extract and their antibacterial activity," International Journal of Current Microbiology and Applied Sciences, vol. 6, no. 6, pp. 1834-1845, 2017.

[10] M. M. Norhasri, M. S. Hamidah and A. M. Fadzil, "Applications of using nano material in concrete: A review," Construction and Building Materials, vol. 133, pp. 91-97, 2017.

[11] A. Korkmaz, "ZnO nanomalzemelerinin yapısal özelliklerinin reaksiyon basıncı ve reaksiyon süresi ile kontrol edilmesi," Yüksek Lisans tezi, Metalurji ve Malzeme Mühendisliği Anabilim Dalı, Frrat Üniversitesi, Elazı ̆̆, Türkiye, 2020.

[12] Ö. Nazikcan, "Farklı üretim özelliğine sahip nanomalzemelerin bitkiler üzerindeki etkilerinin incelenmesi," Yüksek Lisans tezi, İleri Teknolojiler Anabilim Dalı, Anadolu Üniversitesi, Eskişehir, Türkiye, 2015.

[13] E. Esmeray ve O. Özata, "Nanopartiküllerin çevre mühendisliğinde kullanımı ve temel laboratuvar malzemeleri ile gümüş nanopartikül (AgNPs) sentezi," Avrupa Bilim ve Teknoloji Dergisi, c. 16 , ss. $521-527,2019$.

[14] B. Bilgili, "Gümüş nanopartiküllerin (AgNP) sentezi ve karakterizasyonu," Yüksek Lisans tezi, Kimya Anabilim Dalı, Muğla Sitkı Koçman Üniversitesi, Muğla, Türkiye, 2014.

[15] U. B. Şimşek, "Farklı sentez koşullarında sıfır değerlikli nanopartikül üretimi, optimizasyonu ve tekstil boyar maddelerin giderimine uygulanmas1," Yüksek Lisans tezi, Nanoteknoloji ve İleri Malzemeler Anabilim Dalı, Mersin Üniversitesi, Mersin, Türkiye, 2015.

[16] Z. Tüylek, "Küçük şeylerin hikâyesi: nanomalzeme," Nevşehir Bilim ve Teknoloji Dergisi, c. 5, s. 2, ss. 130-141, 2016.

[17] M. Yer, "Gümüş nanopartiküllerin sentezlenmesi ve karakterizasyonu," Yüksek Lisans tezi, Makine Mühendisliği Anabilim Dalı, Selçuk Üniversitesi, Konya, Türkiye, 2012.

[18] T.N. Çevik, "Nanomalzeme ile oluşturulan kompozit alginat boncukları ile ağır metal giderimi," Yüksek Lisans tezi, Çevre Mühendisliği Anabilim Dalı, Akdeniz Üniversitesi, Antalya, Türkiye, 2019.

[19] V. V. Ram, R. Singhal and R. Parameshwaran, "Energy efficient pumpable cement concrete with nanomaterials embedded PCM for passive cooling application in building," Materials Today: Proceedings, vol. 28, no. 2, pp. 1054-1063, 2020.

[20] J. Gonçalves, N. Torres, S. Silva, F. Gonçalves, J. Noro, A. Cavaco-Paulo,A. Riberio and C. Silva, "Zein impart hydrophobic and antimicrobial properties to cotton textiles," Reactive and Functional Polymers, vol. 154, pp. 104664, 2020.

[21] M. Ç. Yavuzaslan, "MgO bazlı nanomalzeme ile atıksulardan renk gideriminin incelenmesi: renk giderim mekanizmasının araştırılması," Yüksek Lisans tezi, Kimya Mühendisliği Anabilim Dalı, Mersin Üniversitesi, Türkiye, Mersin, 2019.

[22] B.T. Çamiç, "Grafen ve Gümüş Nanomalzeme tabanlı saydam iletken elektrot üretimi, karakterizasyonu ve organik güneş hücrelerine uygulanması," Doktora tezi, Fizik Anabilim Dalı, Gebze Teknik Üniversitesi Gebze, Türkiye, 2018. 
[23] T. Gokkurt,, F. Findık,, H. Unal, and A. Mimaroglu, "Extension in shelf life of fresh food using nanomaterials food packages," Polymer-Plastics Technology and Engineering, vol. 51, no. 7 ,pp. 701-706, 2012.

[24] M. Delvaux,, J. Duchet,, P. Y. Stavaux,, R. Legras, and S. Demoustier-Champagne, "Chemical and electrochemical synthesis of polyaniline micro-and nano-tubules," Synthetic Metals, vol. 113, no. 3, pp. 275-280, 2000.

[25] M.İlhan, "LCD ekranlar için nanomalzeme esaslı sıvı kristallerin üretilmesi," Yüksek Lisans tezi, Fizik Anabilim Dalı, Fırat Üniversitesi, Elazı̆̆, Türkiye, 2014.

[26] V. Özkan, "Petrol türevi polimerlere nanopartikül katkılandırarak nanokompozit malzeme üretimi ve karakterizasyonu," Doktora tezi, Makine Mühendisliği Anabilim Dalı, İskenderun Teknik Üniversitesi, Hatay, Türkiye, 2019.

[27] B. Şahyar, "Balıketlerinde tazelik indikatörü olarak ksantin nanobiyosensörü geliştirilmesi ve gıda analizlerinde endüstriyel kullanımı," Doktora tezi, Gıda Mühendisliği Anabilim Dalı, Ege Üniversitesi, İzmir, Türkiye, 2019.

[28] Z. Wang, Z Gu., Y. Hong, Cheng. L and Z. Li, "Bonding strength and water resistance of starch-based wood adhesive improved by silica nanoparticles," Carbohydrate Polymers, vol. 86, no. 1, pp. 72-76, 2011.

[29] K. Roy, C. K. Sarkar and C. K. Ghosh, "Plant-mediated synthesis of silver nanoparticles using parsley (Petroselinum crispum) leaf extract: spectral analysis of the particles and antibacterial study," Applied Nanoscience, vol. 5, no. 8, pp. 945-951, 2015.

[30] B. Elveren, "Green synthesis of metal nanoparticles and their applications as plasmonic substrates," Yüksek Lisans tezi, Biyoteknoloji Anabilim Dalı, İzmir Yüksek Teknoloji Enstitüsü, İzmir, Türkiye, 2018.

[31] E. Sekmek, "Bazı metal nanopartiküllerin çeşitli biyoekstreler ile yeşil sentezi, karakterizasyonu ve grafit elektrot modifikasyonunda kullanımı," Yüksek Lisans tezi, Kimya Anabilim Dalı, Gazi Üniversitesi, Ankara, Türkiye, 2019.

[32] K. P. Kumar, W., Paul and C. P. Sharma, "Green synthesis of gold nanoparticles with Zingiber officinale extract: characterization and blood compatibility," Process Biochemistry, vol. 46, no. 10, pp. 2007-2013, 2011.

[33] H. M. El-Rafie, M. El-Rafie and M. K. Zahran, "Green synthesis of silver nanoparticles using polysaccharides extracted from marine macro algae," Carbohydrate Polymers, vol. 96, no. 2, pp. 403410, 2013.

[34] S. Seshadri, K. Saranya and M. Kowshik, "Green synthesis of lead sulfide nanoparticles by the lead resistant marine yeast, Rhodosporidium diobovatum," Biotechnology progress, vol. 27, no. 5, pp. 1464-1469, 2011.

[35] A. Vágó, G. Szakacs, G. Sáfrán, R. Horvath, B. Pécz and I. Lagzi, "One-step green synthesis of gold nanoparticles by mesophilic filamentous fungi," Chemical Physics Letters, vol. 645, pp. 1-4, 2016.

[36] G. Arun, M. Eyini and P. Gunasekaran, "Green synthesis of silver nanoparticles using the mushroom fungus Schizophyllum commune and its biomedical applications," Biotechnology and Bioprocess Engineering, vol. 19, no. 6, pp. 1083-1090, 2014. 
[37] R. D. Kale and P. B. Kane, "Colour removal using nanoparticles," Textiles and Clothing Sustainability, vol. 2, no. 4, pp. 1-7, 2017.

[38] F. Ge, M. M. Li, H. Ye and B. X. Zhao, "Effective removal of heavy metal ions $\mathrm{Cd}^{2+,} \mathrm{Zn}^{2+}$, $\mathrm{Pb}^{2+}, \mathrm{Cu}^{2+}$ from aqueous solution by polymer-modified magnetic nanoparticles," Journal of Hazardous Materials, vol. 211, pp. 366-372, 2012.

[39] S. Sarkar, S. Chakraborty and C. Bhattacharjee, "Photocatalytic degradation of pharmaceutical wastes by alginate supported $\mathrm{TiO}_{2}$ nanoparticles in packed bed photo reactor (PBPR)," Ecotoxicology and Environmental Safety, vol. 121, pp. 263-270, 2015.

[40] F. Topuz and T. Uyar, "Cyclodextrin-functionalized mesostructured silica nanoparticles for removal of polycyclic aromatic hydrocarbons," Journal of colloid and interface science, vol. 497, pp. 233-241, 2017.

[41] İ. Ateş ve M. Üce, "Lise öğrencilerinin nanobilim ve nanoteknoloji farkındalığı," Gazi University Journal of Gazi Educational Faculty (GUJGEF), c. 37, s. 2, ss. 685-710, 2017.

[42] B. Alan, "Aerobik depo sahalarında nanomalzemelerin davranışları ve atıkların ayrışma prosesleri üzerindeki etkilerinin araştırılması," Yüksek Lisans tezi, Çevre Mühendisliği Anabilim Dalı, Yıldız Teknik Üniversitesi, İstanbul, Türkiye, 2016.

[43] H. Örün, "MnO nanopartiküllerinin sentezi, karakterizasyonu ve fotokatalitik proseste uygulaması," Yüksek Lisans tezi, Kimya Mühendisliği Anabilim Dalı, Selçuk Üniversitesi, Konya, Türkiye, 2018.

[44] Y. Wang, D. O'Connor, Z. Shen, I. M. Lo, D. C. Tsang, S. Pehkonen, S. Pu and D. Hou, "Green synthesis of nanoparticles for the remediation of contaminated waters and soils: Constituents, synthesizing methods, and influencing factors," Journal of Cleaner Production, vol. 226, pp. 540-549, 2019.

[45] A. Soliemanzadeh and M. Fekri, "The application of green tea extract to prepare bentonitesupported nanoscale zero-valent iron and its performance on removal of $\mathrm{Cr}$ (VI): effect of relative parameters and soil experiments," Microporous and Mesoporous Materials, vol. 239, pp. 60-69, 2017.

[46] B. Su, J. Lin, G. Owens and Z. Chen, "Impact of green synthesized iron oxide nanoparticles on the distribution and transformation of As species in contaminated soil," Environmental Pollution, vol. 258, pp. 113668, 2020.

[47] A. A. Romeh and R. A. I. Saber, "Green nano-phytoremediation and solubility improving agents for the remediation of chlorfenapyr contaminated soil and water," Journal of Environmental Management, vol. 260, pp. 110104, 2020.

[48] U. Shanker, V. Jassal and Rani, M, "Green synthesis of iron hexacyanoferrate nanoparticles: potential candidate for the degradation of toxic PAHs," Journal of Environmental Chemical Engineering, vol. 5, no.4, pp. 4108-4120, 2017.

[49] B. Desalegn, M. Megharaj, Z. Chen and R. Naidu, "Green mango peel-nanozerovalent iron activated persulfate oxidation of petroleum hydrocarbons in oil sludge contaminated soil," Environmental Technology \& Innovation, vol. 11, pp. 142-152, 2018.

[50] M. Rani and U. Shanker, "Degradation of tricyclic polyaromatic hydrocarbons in water, soil and river sediment with a novel $\mathrm{TiO}_{2}$ based heterogeneous nanocomposite," Journal of Environmental Management, vol. 248, pp. 109340, 2019. 
[51] T. B. Vidovix, H. B. Quesada, E. F. D. Januário, R. Bergamasco and A. M. S. Vieira, "Green synthesis of copper oxide nanoparticles using Punica granatum leaf extract applied to the removal of methylene blue," Materials Letters, vol. 257, pp. 126685, 2019.

[52] Y. Kuang, Q. Wang, Z. Chen, M. Megharaj and R. Naidu, "Heterogeneous Fenton-like oxidation of monochlorobenzene using green synthesis of iron nanoparticles," Journal of Colloid and Interface Science, vol. 410, pp. 67-73, 2013.

[53] M. Martins, C. Mourato, S. Sanches, J. P. Noronha, M. B. Crespo and I. A. Pereira, "Biogenic platinum and palladium nanoparticles as new catalysts for the removal of pharmaceutical compounds," Water Research, vol. 108, pp. 160-168, 2017.

[54] M. Fazlzadeh, K. Rahmani, A. Zarei, H. Abdoallahzadeh, F. Nasiri and R. Khosravi, "A novel green synthesis of zero valent iron nanoparticles (NZVI) using three plant extracts and their efficient application for removal of Cr (VI) from aqueous solutions," Advanced Powder Technology, vol. 28, no. 1, pp. 122-130, 2017.

[55] C. P. Devatha, A. K. Thalla and S. Y. Katte, "Green synthesis of iron nanoparticles using different leaf extracts for treatment of domestic waste water," Journal of Cleaner Production, vol. 139, pp. 1425-1435, 2016.

[56] M. Hocaoğlu, "Murt yaprağı (Myrtus communis) özütü kullanılarak bakır oksit nanopartiküllerinin yeşil sentezi ve karakterizasyonu: telon blue aglf boyar maddesi adsorbsiyonunun araştırılması," Yüksek Lisans tezi, Kimya Mühendisliği Anabilim Dalı, Mersin Üniversitesi, Mersin, Türkiye, 2017.

[57] D. A. Demirezen, Y. Ş. Yıldız ve D. D. Yılmaz, "Amoxicillin degradation using green synthesized iron oxide nanoparticles: Kinetics and mechanism analysis," Environmental Nanotechnology, Monitoring \& Management, vol. 11, pp. 100219, 2019.

[58] P. Bhattacharya, S. Swarnakar, S. Ghosh, S. Majumdar and S. Banerjee, "Disinfection of drinking water via algae mediated green synthesized copper oxide nanoparticles and its toxicity evaluation," Journal of Environmental Chemical Engineering, vol. 7, no. 1, pp. 102867, 2019.

[59] Ü. A. Güler, "Aljinat-TiO2-alg kompozitinin sentezi ve sulu çözeltilerden tetrasiklin gideriminde kullanılabilirliği ve karakterizasyonu," Karaelmas Science and Engineering Journal, c. 6, s. 1, ss. 130-135, 2016.

[60] B. A. Hemdan, A. M. El Nahrawy, A. F. M. Mansour and A. B. Abou Hammad, "Green solgel synthesis of novel nanoporous copper aluminosilicate for the eradication of pathogenic microbes in drinking water and wastewater treatment," Environmental Science and Pollution Research, vol. 26, no. 10, pp. 9508-9523, 2019.

[61] S. T. Fardood, A. Ramazani, S. Moradi and P. A. Asiabi, "Green synthesis of zinc oxide nanoparticles using arabic gum and photocatalytic degradation of direct blue 129 dye under visible light," Journal of Materials Science: Materials in Electronics, vol. 28, no. 18, pp. 13596-13601, 2017.

[62] S. Joseph and B. Mathew, "Microwave-assisted green synthesis of silver nanoparticles and the study on catalytic activity in the degradation of dyes," Journal of Molecular Liquids, vol. 204, pp. 184-191, 2015.

[63] G. Ç. Sümer, "Hava kirliği kontrolü: Türkiye'de hava kirliliğini önlemeye yönelik yasal düzenlemelerin ve örgütlenmelerin incelenmesi," Uluslararası İktisadi ve İdari İncelemeler Dergisi, c. 13, ss. 37-56, 2014. 
[64] R. Çalhan, "Tekstil nano partiküllerinin biyolojik arıtma sisteminde davranışı ve etkileri," Yüksek Lisans tezi, Çevre Mühendisliği Anabilim Dalı, Pamukkale Üniversitesi, Denizli, Türkiye, 2012.

[65] M. Abbasi, F. Saeed and U. Rafique, "Preparation of silver nanoparticles from synthetic and natural sources: remediation model for PAHs," In IOP Conference Series: Materials Science and Engineering, vol. 60, no. 1, pp. 012061, 2014.

[66] N. Gandhi, D. Sirisha, and V. C. Sharma, "Microwave-mediated green synthesis of silver nanoparticles using Ficus elastica leaf extract and application in air pollution controlling studies," International Journal of Engineering Research and Applications, vol. 4, no. 1, pp. 61-72, 2014.

[67] A. Palliyarayil, P. S. Prakash, S. Nandakumar, N. S. Kumar and S. Sil, "Palladium nanoparticles impregnated activated carbon material for catalytic oxidation of carbon monoxide," Diamond and Related Materials , vol. 107, pp. 107884, 2020.

[68] R. Magudieshwaran, J. Ishii, K. C. N. Raja, C. Terashima, R. Venkatachalam, A. Fujishima and S. Pitchaimuthu, "Green and chemical synthesized $\mathrm{CeO}_{2}$ nanoparticles for photocatalytic indoor air pollutant degradation," Materials Letters, vol. 239, pp. 40-44, 2019.

[69] I. Karaduman, A. A. Güngör, H. Nadaroğlu, A. Altundaş ve S. Acar, "Green synthesis of $\gamma$-Fe $2 \mathrm{O} 3$ nanoparticles for methane gas sensing," Journal of Materials Science: Materials in Electronics, vol. 28, no. 21, pp. 16094-16105, 2017.

[70] Ü. Şahin, T. Tunç ve S. Örs, "Yeraltı suyu kirliliği açısından atık su kullanımı," International Journal of Agricultural and Natural Sciences, c. 4, s. 1, ss. 33-39, 2011.

[71] A. Toli, A. Varouxaki, C. Mystrioti, A. Xenidis and N. Papassiopi, "Green synthesis of resin supported nanoiron and evaluation of efficiency for the remediation of $\mathrm{Cr}$ (VI) contaminated groundwater by batch tests," Bulletin of Environmental Contamination and Toxicology, vol. 101, no. 6, pp. 711-717, 2018.

[72] W. B. Ayinde, W. M. Gitari, M. Munkombwe and S. Amidou, "Green synthesis of Ag/MgO nanoparticle modified nanohydroxyapatite and its potential for defluoridation and pathogen removal in groundwater," Physics and Chemistry of the Earth, Parts A/B/C, vol. 107, pp. 25-37, 2018.

[73] F. Zhu, S. He and T. Liu, "Effect of $\mathrm{pH}$, temperature and co-existing anions on the Removal of $\mathrm{Cr}$ (VI) in groundwater by green synthesized nZVI/Ni," Ecotoxicology and Environmental Safety, vol. 163, pp. 544-550, 2018.

[74] F Zhu. S. Ma, T. Liu and X. Deng, "Green synthesis of nano zero-valent iron/Cu by green tea to remove hexavalent chromium from groundwater," Journal of Cleaner Production, vol. 174, pp. 184-190, 2018.

[75] L. Qian, W. Zhang, J. Yan, L. Han, Y. Chen, D. Ouyang and M. Chen,'Nanoscale zero-valent iron supported by biochars produced at different temperatures: Synthesis mechanism and effect on Cr(VI) removal," Environmental Pollution, , vol. 223, pp. 153-160, 2017.

[76] L. Katata-Seru, T. Moremedi, O. S. Aremu and I. Bahadur, "Green synthesis of iron nanoparticles using Moringa oleifera extracts and their applications: removal of nitrate from water and antibacterial activity against Escherichia coli," Journal of Molecular Liquids, vol. 256, pp. 296-304, 2018. 
[77] T. C. Oğuz, "İçme suyu arıtımında yaygın olarak karşılaşılan su kalite problemleri ve arıtımı için çözüm önerileri," Uzmanlık tezi, T.C. Orman ve Su İşleri Bakanlığı, Ankara, Türkiye, 2015. 